\title{
Randomized trial of thymectomy in myasthenia gravis
}

\author{
Gil I. Wolfe ${ }^{1}$, Henry J. Kaminski ${ }^{2}$, Joshua R. Sonnett ${ }^{3}$, Inmaculada B. Aban ${ }^{4}$, Hui-Chien Kuo ${ }^{4}$, Gary R. Cutter ${ }^{4}$ \\ ${ }^{1}$ Department of Neurology, University at Buffalo Jacobs School of Medicine and Biomedical Sciences/SUNY, Buffalo, NY, USA; ${ }^{2}$ Department of \\ Neurology, George Washington University Medical Center, Washington DC, USA; ${ }^{3}$ Section of General Thoracic Surgery, Columbia University \\ Medical Center, New York, NY, USA; ${ }^{4}$ Department of Biostatistics, University of Alabama at Birmingham, Birmingham, AL, USA \\ Correspondence to: Gil I. Wolfe, MD, FAAN. Irvin and Rosemary Smith Professor and Chair, Department of Neurology/Jacobs Neurological Institute, \\ University at Buffalo Jacobs School of Medicine and Biomedical Sciences/SUNY, Buffalo General Medical Center, 100 High St., Buffalo, NY 14203- \\ 1126, USA. Email: gilwolfe@buffalo.edu. \\ Provenance: This is an invited Correspondence commissioned by the Section Editor Gang Shen, MMSC (The Second Affiliated Hospital Zhejiang \\ University School of Medicine, Hangzhou, China). \\ Response to: Tzankov A. Commentary on "Randomized trial of thymectomy in myasthenia gravis". J Thorac Dis 2016;8:E1420-E1422. \\ Bourque PR, Warman Chardon J. A crucial first randomized controlled trial of thymectomy in non-thymomatous myasthenia gravis. J Thorac Dis \\ 2016;8:E1375-E1378.
}

Submitted Dec 02, 2016. Accepted for publication Dec 02, 2016.

doi: $10.21037 /$ jtd.2016.12.80

View this article at: http://dx.doi.org/10.21037/jtd.2016.12.80

\section{To the Editor:}

We appreciate the wide interest in the results from the international extended transsternal thymectomy trial in non-thymomatous myasthenia gravis (MG) (1). Correspondence has been received from several medical communities including neurologists, thoracic surgeons, and pathologists. And we thank Tzankov and Bourque and Warman Chardon for their gracious comments.

Tzankov (2) frames the role of thymectomy in both thymomatous and non-thymomatous MG while Bourque and Warman Chardon (3) summarize the historical record of randomized, controlled treatment trials in the disease. Both single out the evidence gap related to thymectomy we worked to bridge with our trial. The practice parameter by Gronseth and Barohn (4) in 2000 explicitly called for such an effort. There are several points raised by the authors we wish to clarify. The first is the decision to use minimal manifestation status (MMS) as opposed to remission as the clinical endpoint that dictated prednisone dosing changes. Remission in MG, especially when formally defined (5), is relatively uncommon (15-25\%), no matter the intervention $(6,7)$. MMS is more commonly encountered and is accepted as a favorable outcome. A clinical status of MMS or better was defined as the treatment goal in the recently published international consensus guidance for MG management (8). As for the thymic tissue, further analysis of the resected specimens and correlation of histopathological findings with clinical outcomes are in the works.

There is no question that conducting randomized surgical trials presents challenges, and the thymectomy study was no different. Disease duration and upper age limits were modified to boost recruitment; these were the only changes made over the 9-year duration of the trial. We did consider loosening the entry criteria that forbade any immunosuppressive therapy outside of corticosteroids, but concluded such agents would cloud interpretation of study results. Similarly, we weighed the advantages and disadvantages of permitting less invasive thymectomy approaches, but decided against this allowance as well, mandating that the extended transsternal technique be utilized. We were conducting the first randomized trial of thymectomy and felt it imperative to first demonstrate whether there was benefit to an as-complete resection as possible. Nevertheless, our inference is that a similar constellation of benefits can be expected with less invasive approaches as long as the surgeon's intent is to perform as complete a thymectomy as possible.

The role of thymectomy in double-seronegative and muscle-specific kinase (MuSK) antibody-positive MG deserves final comment. Thymectomy does appear to have a positive impact in double-seronegative patients (7), an observation that may reflect the likelihood that many of 
these patients actually harbor anti-acetylcholine receptor antibodies when tested with cell-based assays that cluster the receptor, mimicking the architecture of the postsynaptic membrane $(9,10)$. In most reports, thymectomy in MuSK-antibody positive patients seems to have little if any favorable impact $(7,8)$, providing further emphasis to the need to individualize management approaches for patients with MG.

\section{Acknowledgements}

Funding: This work was supported by NIH/NINDS U01 NS042685, the Muscular Dystrophy Association, and the Myasthenia Gravis Foundation of America.

\section{Footnote}

Conflicts of Interest: The authors have no conflicts of interest to declare.

\section{References}

1. Wolfe GI, Kaminski HJ, Aban IB, et al. Randomized Trial of Thymectomy in Myasthenia Gravis. N Engl J Med 2016;375:511-22.

2. Tzankov A. Commentary on "Randomized trial of thymectomy in myasthenia gravis". J Thorac Dis 2016;8:E1420-E1422.

3. Bourque PR, Warman Chardon J. A crucial first

Cite this article as: Wolfe GI, Kaminski HJ, Sonnett JR, Aban IB, Kuo HC, Cutter GR. Randomized trial of thymectomy in myasthenia gravis. J Thorac Dis 2016;8(12):E1782-E1783. doi: $10.21037 /$ jtd.2016.12.80 randomized controlled trial of thymectomy in nonthymomatous myasthenia gravis. J Thorac Dis 2016;8:E1375-E1378.

4. Gronseth GS, Barohn RJ. Practice parameter: Thymectomy for non-thymomatous autoimmune myasthenia gravis (an evidence-based review). Neurology 2000;55:7-15.

5. Jaretzki A 3rd, Barohn RJ, Ernstoff RM, et al. Myasthenia gravis: recommendations for clinical research standards. Task Force of the Medical Scientific Advisory Board of the Myasthenia Gravis Foundation of America. Neurology 2000;55:16-23.

6. Grob D, Brunner N, Namba T, et al. Lifetime course of myasthenia gravis. Muscle Nerve 2008;37:141-9.

7. Baggi F, Andreetta F, Maggi L, et al. Complete stable remission and autoantibody specificity in myasthenia gravis. Neurology 2013;80:188-95.

8. Sanders DB, Wolfe GI, Benatar M, et al. International consensus guidance for management of myasthenia gravis: Executive summary. Neurology 2016;87:419-25.

9. Jacob S, Viegas S, Leite MI, et al. Presence and pathogenic relevance of antibodies to clustered acetylcholine receptor in ocular and generalized myasthenia gravis. Arch Neurol 2012;69:994-1001.

10. Leite MI, Jacob S, Viegas S, et al. IgG1 antibodies to acetylcholine receptors in 'seronegative' myasthenia gravis. Brain 2008;131:1940-52. 